\title{
Collaboration experience in the Supply Chain of Knowledge and Patent Development
}

\section{$\underline{\text { Authors and affiliations }}$}

Alessandra Alletto, Universty of Palermo, alessandra07@hotmail.it

*Manfredi Bruccoleri, University of Palermo,manfredi.bruccoleri@unipa.it

Erica Mazzola, University of Palermo,erica.mazzola@unipa.it

Usha Ramanathan, Nottingham Trent University, usha.ramanathan@ntu.ac.uk

*Corresponding author 


\begin{abstract}
In this paper we aim at understanding the role of collaboration experience in supply chains of knowledge (SCoK). The SCoK of a company is its supply chain not related to the flow of physical goods but to the flow of $R \& D$ commodities. $R \& D$ commodities are for example patents, technologies, research services, studies, and projects, and, in high-tech industries, their development and commercialization is considered as important as real products. To accomplish our aim in this paper we fulfil the following research objectives: 1) investigate the relationship between the collaboration experience in SCoK and the propensity of the firm to develop new patents; 2) examine how the structural embeddedness of the firm within its SCoK mediates this relationship. We ground our conceptual model on the supply chain, open innovation and social capital literatures and empirically test our hypotheses on a cross-sectional dataset of 208 biotech companies that have signed $612 \mathrm{SCoK}$ agreements in the years 2006-2010. The key findings of this study are: first, accumulating experience in SCoK collaborations facilitates the development of new patents; second, being central and bridging structural holes within the SCoK are two means by which the experience in SCoK collaborations is translated into new patents.
\end{abstract}

Keywords: Supply Chain of Knowledge, Collaboration experience, Open Innovation, Social Capital 


\section{Introduction}

Increasingly in the past few decades several companies have established vertical collaborations along their supply chains. Many researchers have focused on the role of such collaborations in companies' new product development (NPD) (Büyüközkan, and Arsenyan, 2012; He et al., 2014). For example, many studies on collaborative buyer-supplier relationships investigated how building social capital creates value for companies participating in NPD and increases NPD performance (Cousins et al., 2006; Lawson et al., 2008; Villena et al. 2011; Bunduchi, 2013; Kim, 2014). These studies suggest that building social capital through collaborations with buyers and suppliers allows the focal company to gain access to and leverage information volume, diversity and quality (Koka and Prescott, 2002; Autry and Griffis, 2008). Social capital promotes cooperative behaviour among supply chain members which in turn improves NPD performance.

In other words, in the supply chain management literature the linkages among three elements, namely supply chain collaboration in NPD, social capital arising from buyer-supplier relationships, and NPD performance, have been largely investigated.

But things are different in high-tech industries such as nanotechnology or biotechnology. In fact, in these industries 'patents' often represent the final products of the company (Pisano, 1991). The core business of these companies often relies in conducting R\&D activities, and also their main revenues come from the selling of the outputs of such R\&D activities. R\&D commodities, being the outcomes of research activities, are for example patents, technologies, research services, studies, projects, etc. The recent research on Open Innovation (OI) empirically evidences that innovation is not the product of firm's autonomous research (Chesbrough, 2003; Hsuan and Mahnke, 2011; Battistella and Nonino, 2013). In today's fast high-tech industries, the innovation performance of a company cannot be understood without considering the external organizational relationships that it maintains with different kinds of partners such as suppliers, universities, private and public research centers, etc. In the OI paradigm it is well known that purchasing (inflow) and selling (outflow) R\&D commodities influence firm innovation performance (Rothaermel, 2001; Laursen and Salter, 2006; Lichtenthaler, 2009).

As such, in these industries the traditional material flow (physical goods) supply chain is replaced by the knowledge flow (R\&D commodities) supply chain. Here, the knowledge inflow is generally achieved by purchasing R\&D from other companies, for example by licensing-in patents. Analogously, knowledge outflow is accomplished by directly selling of R\&D commodities to other companies (for example by licencing-out patents). In this case, the selling company acts as the supplier of R\&D (in the form of 'commodities') and the purchasing company acts as the buyer of 
R\&D. In this paper, we name this type of supply chain as 'Supply Chain of Knowledge (SCoK)', being the company's inbound and outbound flows related to intangible commodities.

As SCoK is a newly developing area of research, we do not have enough literature support to see how collaboration is helping the new patent development of high-tech companies. However, comprehending the role of collaboration experience with SCoK partners and the way the company position itself within this network, would be of great value for R\&D managers involved in designing and managing their supply chain of knowledge in order to increase the company's patent productivity. Also, by studying this phenomenon our theoretical contribution is twofold. First we contribute to the existing literature on Supply Chain (SC) management and NPD by applying acknowledged theoretical frameworks that have already been empirically tested in traditional supply chains, in the supply chain of knowledge. Second, we argue that considering and studying the position of the company within the SCoK, over the whole innovation network (which instead also includes other kinds of partnerships such as R\&D alliances and Joint Ventures), could bring very interesting insights in understanding the paradigm of $\mathrm{OI}$ and the evolution of the business models of companies belonging to high tech industries.

Hence, in this paper, we aim at investigating the role of collaboration experience in the SCoK by: 1) investigating the relationship between the collaboration experience in SCoK and the propensity of the firm to develop new patents; 2) examining how the structural embeddedness of the firm within its SCoK mediates this relationship. To achieves these research objectives, we study the linkages among the following three elements a) supply chain collaboration in new patent development, b) social capital arising from SCoK buyer-supplier relationships, and c) new patent performance analogously to what is usually studied in physical supply chains.

In line with the literature on SC and NPD, in this paper we hypothesize that same linkages exist in high-tech industries where product are substituted by patents. Based on our initial research in this area, our research posits that collaboration experience in the SCoK positively influences the company's patent productivity, being this relationships partially mediated by the social capital arising from SCoK buyer-supplier relationships.

In order to achieve the proposed research objectives, we use information from the participants in SCoK, by collecting data from the BioWorld database, a US companies' database that offers a library of information, analysis and data on the developments of the global bio-pharmaceutical industry. The following sections are organised as follows: Section 2 reports the theoretical background and the development of the hypotheses. Empirical setting and research methods are described in Section 3. In Section 4 we present the results of the data analysis, while the discussion on findings are presented in Section 5. Conclusions and future directions of this study are reported in the last Section. 


\section{Theoretical background and hypotheses development}

To make our research objectives clear, it is imperative to specify the difference between material flow SCs and SCoK. In the high-tech industries the products are replaced by the patents and the physical goods supply chain is replaced by the SCoK. To illustrate an example of SCoK, we use the following companies from the biotech industry: MorphoSys AG, ImmunoGen Inc., Amgen, and Takeda Pharmaceutical Co. Ltd. The formal structure of their R\&D supply agreements is mapped in Figure 1. We found that Amgen licensed-out 13 molecules to Takeda Pharmaceutical Co. Ltd to develop medicines for serious illness across a range of therapeutic areas, including oncology, inflammation, and pain. On the other side, Amgen licensed-in the exclusive right to use the "Maytansinoid Targeted Antibody Payload" technology to develop anticancer therapeutics patent family from ImmunoGen Inc., which, in turn, has licenced-in the "HuCAL" technology from MorphoSys AG. These SCoK relationships do not necessarily refer to the same molecule, but to R\&D purchasing and selling agreements related to Amgen with its suppliers and buyers of knowledge.

-----Please insert Figure 1 about here----

By considering companies as social actors, previous researchers have built on Coleman's (1988) initial notion that a network structural position denotes social capital benefits. Social capital is defined as a valuable asset that stems from access to resources made available through social relationships (Coleman, 1988; Granovetter, 1992). A core premise of the social capital theory is the notion of embeddedness. The seminal work of Granovetter (1973) postulates that during exchange episodes, actors do not behave with perfect economic rationality because they are embedded within social networks with other actors, who are able to provide greater access to resources, information, and influence than would not otherwise be available. Granovetter $(1985,2005)$ suggests that one the most forms significant form of embeddedness within the network is the structural embeddedness, defined as the pattern of connections between actors within the overall structural form of their relations.

Social network analysis has emerged as a valuable tool for assessing social structures of many types (e.g. Autry and Griffis, 2008; Min et al. 2008). In other words, social capital represents the aggregate value of a company's network structural components and relational attributes, while social network analysis is particularly suited to empirically measure this value, thanks to its ability to simultaneously assess multiple structural connections and the relationships these connections represent. 
In this research, we refer to the structural embeddedness dimension of Social Capital this is mainly because depending on the intensity and frequency of the interactions, the relationships can be strong or weak. Thus tie strength determines innovation benefits, in terms of product or patent development, that can accrue from a network position (Granovetter, 1973; Ahuja, 2000; Soh, 2003; Mazzola et al., 2014). For example, strong ties are linked to efficient execution and weak ties to bridging of otherwise disparate sub-networks. However, an additional theoretical view is developed by Burt, (1992), who highlighted the importance of structural holes; structural holes occur when an actor ties two other actors that are otherwise unconnected and thus form a relationship of non-redundancy between actors. Different authors have explored the benefits of the structural dimension of social capital on firm's performance. Some of them are reported in Table 1 together with social network analysis measures that are commonly used to assess structural embeddedness.

----Please insert Table 1 about here----

Given these premises, and grounding our theory on the Open Innovation literature, Supply Chain Management literature, and Social Capital literature, we now attempt to develop research hypotheses regarding the linkages among SCoK collaborations, social capital, and new patent development. Specifically, we investigate three different relationships as depicted in Figure 2: Collaboration Experience in SCoK and New Patent Development (Path A); Structural Embeddedness in SCoK and New Patent Development (Path B); and Collaboration Experience in SCoK and New Patent Development as mediated by Structural Embeddedness in SCoK (Path C+B).

----Please insert Figure 2 about here---

\subsection{Collaboration experience in SCoK and new patent development (Path A)}

The role of SC collaborations with suppliers, customers or other supply chain players in improving the performance of the new product development has been very much investigated in SC literature. Several forms of collaboration with suppliers and customers in NPD have been deeply analysed: early supplier involvement in new product development (Koufteros et al., 2005; Johnsen, 2009; Garengo and Panizzolo, 2013); supplier investment (Song et al., 2005; Song and Di Benedetto, 2008); supplier integration (Caniato and Größler, 2015; Petersen et al., 2005; Ettlie and Pavlou, 2006; Swink et al., 2007); supplier development (Krause et al., 2007); supplier innovation generation (Jean et al., 2012); customer involvement (Bendoly et al., 2009; Romero and Molina, 2011); customer integration (He et al., 2014). 
Furthermore, the literature on open innovation largely agrees that in today's highly competitive environment the propensity to develop innovations may not be simply the result of knowledge and capabilities that firms can find and develop in-house; but it depends on the effectiveness with which they can gain access to external sources of technological knowledge and skills (Kline and Rosenberg, 1986; Kogut, 1988; Chesbrough, 2003; Laosirihongthong et al., 2014). Despite their advocated benefits, it has been proved that the knowledge impending from supply chain collaborations is difficult to be capitalized (Barrat, 2004). However, having a high collaboration experience with other supply chain members enables the company to learn about each other, increases its absorptive capacity, and intensifies the value of exchanged knowledge. Zahra and George (2002) define absorptive capacity as a set of organizational routines and processes by which companies acquire, assimilate, transform and exploit knowledge to produce dynamic capabilities. In other words, the company's overall collaboration experience is a vehicle for valuable knowledge, for new organizational learning, for helping the collaborating companies to eliminate dysfunctional routines, repeat successful procedures and prevent strategic blind-spots (Hamel et. al, 1989; Mody, 1990, Teece and Pisano, 1994). This is mainly because the organizational experience from collaborations increases the company's information and knowledge absorptive capacity (Nelson and Winter, 1982; Cohen and Levinthal, 1990; Zhara and George, 2002). Long-term collaborations help the companies to develop schemas and better understanding of the new information - its new product development processes (Ritter et al., 2004). Also, collaboration experience increases the level of trust, reduces the likelihood of opportunistic behavior among the supply chain members, lowers inter-organizational safeguard mechanisms, and builds better knowledge flows (Gulati, 1995; Zaheer and Venkatraman, 1995; Msanjila and Afsarmanesh, 2011; Ramanathan and Gunasekaran, 2014).

Summing up, advantages coming from collaboration experience in the physical goods supply chain have been empirically demonstrated in the operations and supply chain management literature. We strongly believe that these benefits still hold for the collaborations experience in the SCoK. In this case, when the company's core business is to develop and sell patents and other R\&D commodities instead of physical products, and even its purchasing and selling activities mainly refer to $R \& D$ commodities, the collaboration experience in the SCoK brings advantages in terms of R\&D commodities development, e.g. new patent development. For instance, a company who wishes to purchase a given R\&D service and, thus, enters a given collaboration with a SCoK member cannot take for granted benefits on its patent development process. We, indeed, adopt an absorptive capacity perspective to understand the success of collaborations as a result of a self-sustaining dynamic process in which past collaborations (for example, patent in-licensing) trigger the development of collaborative capital as a mean to orchestrate new collaborations (Cohen and Levinthal, 1990; Powell 
et. al, 1999; Zhara and George, 2002). This reasoning supports the argument that cumulating experience from SCoK collaborations impacts companies' ability to develop new patents. Accordingly we posit our first research hypothesis as follows:

H1 High level of collaboration experience in SCoK will be associated with higher number of newly developed patents

\subsection{Theory underlying structural embeddedness in SCoK and new patent performance (Path B)}

Progressively in the last decades companies opened their solid boundaries to let valuable knowledge flow from outside and vice-versa, by collaborating with different partners, including suppliers or buyers, competitors, and universities or research organizations (Gassmann and Enkel, 2004; Laursen and Salter, 2006; Tsai and Wang, 2009; Gassmann et al., 2010; Chiang and Hung, 2010; Dahlander and Gann, 2010; Huang et al., 2010). This tendency to create multiple relationships with several partners has embedded companies in complex webs of inter-firm networks (Wu, 2008). According to the Social Capital theory these networks act as conduits of inter-personal and inter-organizational resources, knowledge and information flow, becoming a crucial feature for increasing company's performance (Sammarra and Biggiero, 2008). The Social Capital theory is useful in the analysis of benefits of structural position (embeddedness) of the company within its network. Structural embeddedness is the value of the company structural position in a complex network, comprising multiple dyadic relationships, that involves informational and reputational benefits. Academic literature on the social capital is showing advantages of structural embeddedness in terms of new product development. For instance, Soh (2003) finds that a company enhances its innovative performance measured in terms of new product awards by increasing its centrality position compared to others. Pérez-Luño et al. (2011) and Li et al. (2013) argue that the likelihood to develop new or significant improved products/services is positively related to company's position into the network. Even the supply chain management literature has recently used Social Capital theory to posit that the structural embeddedness of businesses within their multiple supply chains may result in comparable operational and new product development advantages. For instance Kim (2014) examines the potential of supplier structural embeddedness to improve the performance of a buying company. Villena et al. (2011) evaluate how social capital in its cognitive, relational, and structural forms contributes to value creation within buyer-supplier relationships. Min et al. (2008) develop a conceptual framework that depicts how supply chain identity and social capital contribute to successful supply chain management. Cousins et al. (2006) develop a model that suggests the impact of formal and informal socialization processes on the creation of relational capital between buyers 
and suppliers. Autry and Griffis (2008) illustrate several important ways companies' investments in supply chain structural and relational embeddedness generate differentiable performance.

Thus, our second line of enquiry (Path B), drawing on the Social Capital theory and transposing existing findings from the supply chain of physical goods into the supply chain of knowledge, examines how being structural embedded in SCoK enhances company's ability to develop new patents. In particular, we refer to two social network analysis measures for structural embeddedness, i.e. centrality and structural holes position (Ahuja, 2000; Burt, 1992, 2004; Borgatti et al., 2002).

A company with a central position in a network benefits from the information volume, i.e. a dimension emphasizing the quantity of information that a company can access and acquire through its position in the network of inter-firm ties (Koka and Prescott, 2002). Central companies with a higher number of ties have more access to key information that also reduces search costs and enhances efficiency of search and transfer process (Cyert and March, 1963). As a result a higher centrality increases company's specialization and, eventually, supports its patent development process (Ahuja, 2000; Salman and Saives, 2004; Gilsing et al. 2008; Vanhaverbeke et al. 2012).

Scholars suggest structural holes position as second measure of network structural embeddedness (Burt, 1992, 2004; Ahuja, 2000; Zaheer and Bell, 2005; Padula, 2008). A company having a structural holes position in the network acts as a bridge between different companies otherwise disconnected in the network (Koka and Prescott, 2002; Benassi and Di Minin, 2009). By relying on the brokerage opportunities created by an open social structure (Burt, 1992), a structure holes position provides the ego company with information diversity (Burt, 1992), i.e. a dimension emphasizing control and participation of information and resources between different and often unconnected groups in the network (Burt, 2000). As a result a structural holes position increases company's new understanding of new threats and opportunities coming from the network and, eventually, supports its patent development process.

To sum up, we propose a positive relationship between the two attributes of company's structural embeddedness in the SCoK and its ability to create novelty. Accordingly, we posit our next research hypotheses as follows.

H2.a Being centrally located in the SCoK, the company will be associated with higher number of newly developed patents.

H2.b Having a bridging structural holes position in the SCoK, the company will be associated with higher number of newly developed patents.

\subsection{Mediating role of structural embeddedness $($ Path $C+B)$}


In the previous section, we argued that collaboration experience influences positively the company's propensity in developing new patents. We also stated that this positive effect is due to a number of virtuous behaviors such the increase of absorptive capacity, the development of schemas and routines, the growth of trust, the reduction of the opportunistic behavior, the decrease in inter-organizational safeguard mechanisms, and the improvement of knowledge flows. This means that, although we expect the collaboration experience to yield performance benefits, there are questions related to how the given effect occurs and what intervenes between the antecedent and the consequence. The central or structural holes position within the SCoK can act to mediate this relationship. The reasoning for hypothesizing this mediating effect is that the structural position of the company in the SCoK can be seen as a consequence of the collaboration experience. By maturating collaboration experience the company develops gradually overtime an extended network of relationships that locate the company itself in a strategic position within the SCoK and increase its structural embeddedness (Granovetter, 1973). However, it will be difficult to state that a company by maturing a collaboration experience would deliver superior performance. Rather, the collaboration experience shapes structural embedded mechanisms that in turn shape a certain level of information volume and diversity flowing through the company, and it the structural embeddedness that leads to superior performance.

The mediating effect of structural embeddedness occurs because the collaboration experience itself could create internal tensions if it does not contribute to position the company in a central and structural holes position. For example, the company could mature a high level of collaboration experience by just keeping collaborating with only one or very few suppliers and/or customers overtime. Repeated collaborations with the same partners surely bring advantages in terms of encouraging cohesive social interaction and personal relationship, promoting close observation and interaction, accessing specific and tacit knowledge, and other virtuous relational mechanisms (Krause et al. 2007; Tiwana, 2008; Khoja et al. 2010). On the other hand, danger of such repeated collaborations might reduce the advocated benefits coming from the exchanges of high level of information volume and diversity that usually come from being structurally embedded in the supply chain. For instance, some studies reported negative effect of embeddedness on performance when it brings redundant information and high maintenance cost (Rowley et al. 2000; Tiwana, 2008).

In sum, we argue that differences in company's positioning in SCoK may be found to mediate the relationship between SCoK collaboration experience and company's ability to develop new patents. The above reasoning led us in developing the following research hypotheses.

H3.a The company's centrality in SCoK will mediate the relationship between the collaboration experience in SCoK and the number of newly developed patents. 
H3.b The company's structural holes position in SCoK will mediate the relationship between the collaboration experience in SCoK and the number of newly developed patents.

\section{Research Methods and data description}

\subsection{Research method}

The research method adopted to test the theory-based hypotheses consists of a secondary data set analysis. Secondary data analysis consists of analysing data collected by someone else (not specifically for the research questions at hand) and using the data to get a better understanding of a theoretical concept (Frankfort-Nachmias and Nachmias, 1992; Stewart, 1984). Different sources are generally used to collect such types of data (e.g. annual reports and organizational statistics, industry statistics provided by government agencies, etc.). In this research, we understand the role of R\&D collaborations of various high-tech $\mathrm{R} \& \mathrm{D}$ companies using an extensive reading of annual statements and company websites, but overall using data from BioWorld database.

\subsection{Sample and Data}

The research setting for this study is the biotechnology industry. We chose this industry because it is characterised by a high level of $\mathrm{R} \& \mathrm{D}$ commodities exchanges, which is very much related to our research objectives and hypotheses (Rothaermel and Deeds, 2004; Sabatier et al., 2010; Billitteri et al., 2013).

We collect data from the BioWorld database. BioWorld is a US companies' database, owned by Thomson Reuters and compiled by the North Carolina Biotechnology Center, that offers a library of information, analysis and data on the developments of the global bio-pharmaceutical industry. BioWorld archives also include detailed descriptions of inter-firm agreements signed by biopharmaceutical companies in the last twenty years. Use of data from BioWorld was also adopted in previous research study by Birch (2008) and Al-Laham et al. (2008). For this study, we collected data on selling/purchasing of R\&D commodities between companies in the years 2006-2010. We selected all public companies in BioWorld, specifically 208, to ensure availability and reliability of firm-attribute data. Thus, by selecting all the public firms in the dataset, no selection bias is present in our sample.

We completed our dataset by integrating publicly available information. Specifically, we referred to the USPTO (United States Patent and Trademark Office) database to gather data about patents for all companies in the sample, including those based outside US. We used US patents instead of other national patent systems "to maintain consistency, reliability and comparability as patenting systems 
across nations differ in the application of standards, system of granting patents, and value of protection granted" (Ahuja, 2000: 434). Also we used companies' annual reports to collect economic and financial information.

\subsection{Operationalization of model's constructs}

To operationalize our model constructs which are reported in Figure 2 (namely Collaboration Experience, Centrality, Structural Holes, New Patent Development) we identify a number of variables that we then measured by using data available in our secondary data sources. By using BioWorld database, USPTO database, and firms' annual reports, we are able to collect all the needed information to test our hypotheses. So while we are conscious that a researcher can more easily extrapolate meaning from primary data (Riccobono et al. 2014), in our case secondary data sourcing revealed to be a suitable method to collect data. In what follows, we report the operationalization and measuring process for each construct/variable.

\subsubsection{Dependent variable}

We measure the dependent variable, namely the new patents developed by the biotechnology company (NPatD), by counting the total number of patents introduced by each company in the US market throughout 2010-2012. Several factors indicate that patent propensity provides a good measure of firm's innovative output in the biotechnology industry (Rothaermel and Deeds, 1994). In biotechnology industry, for example, due to the complex and risky drug development pipeline, one innovation may generate several patents and never lead to the introduction of a new-finished product into the market. Thus, compared to new product development, patents provide reliable measures of innovation, regardless of whether innovations get to market. Moreover, biotechnology companies file for patents also to protect their intellectual property. In fact, since the incremental nature of biotechnological innovation (Orsenigo, 1989), by patenting the company can try to protect its innovations already in the earlier-stage of drug development pipeline - often well before a product or process is introduced to the market. Further, intellectual property protection for newly developed molecules and processes offers significant benefits for the winner of a patent race: a 20-year monopoly in the U.S. and Canada (Rothaermel and Deeds, 1994). Finally, several authors have used patents to operationalize the innovative output of biotechnology companies and as a measure of innovation output in collaborative relationships. Among them: Shan et al., 1994; Arundel and Kabla, 1998; Deeds and Decarolis, 1999; Ahuja, 2000; Salman and Saives, 2005; Schilling and Phelps, 2007; Gilsing et al., 2008; Padula, 2008; Vanhaverbeke et al. 2009; Vanhaverbeke et al., 2012. 
We adopt a moving window approach to assess different lag specifications between collaboration experience in SCoK, structural embeddedness in SCoK and new patent development (Bae and Gargiulo, 2004; Salman and Saives, 2005); according to this approach, we calculate the dependent variable by considering the 3 years (from 2010 to 2012) succeeding the 5-year companies' agreements observations (from 2006 to 2010).

\subsubsection{Independent variables}

By recurrently purchasing and selling R\&D commodities, companies develop their familiarity in dealing with buyer-supplier relationships and exchanged knowledge exploitation. In this perspective, we consider the following explanatory variable as measure of the experience accumulated by each company in dealing with exchanging of R\&D commodities: collaboration experience in SCoK. Specifically, we count (Coll_Exp_SCoK) how many times each biotech company purchases or sells R\&D commodities throughout the period 2006-2010.

To measure Centrality and Structural Holes (Koka and Prescott, 2002), we built a matrix containing all the agreements referred to R\&D selling/purchasing exchanges in the years 2006-2010 and use it as input for UCINET VI (Borgatti et al., 2002), a network analysis software that computes network variables by using dyadic data (Salman and Saives, 2005; Padula, 2008). In particular, by following prior literature (Bonacich, 1987; Koka and Prescott, 2002; Salman and Saives 2005), we employ eigenvector centrality to measure centrality in the SCoK. This measure is calculated by using both direct and indirect ties; so it provides an overall idea about the position of the company in the SCoK. To evaluate the level of brokerage of the company (Structural Holes) we use the score of constraint at node-level of each company (Burt, 1992; Zaheer and Bell, 2005). According to Burt (1992) network constraint effectively measures company's lack of access to structural holes. In other words, the higher the company's constraint value, the lower structural holes exist in its network. Accordingly, we compute this variable as one minus the company's constraint score.

\subsubsection{Control Variables}

Other factors that are not listed above may also influence the number of developed patents. To avoid possible confounding effects, we introduce some control variables. We first include the natural logarithm of the company's Age as control variable (Soh, 2003, Zaheer and Bell, 2005, Wu, 2008, Vanhaverbeke et al., 2009, Perez-Luño et al., 2011), by counting the number of years from the date of establishment to 2010. Next, we compute the natural logarithm of average number of employees in the years 2006-2010 as a proxy of the Size of each company in the sample (Ahuja, 2000; Soh, 2003, Acquaah, 2007). We also control for Product stock, since it reflects the level of technological capital 
and R\&D know-how of a company (Shilling and Phelps, 2007). Specifically, we count the number of company products introduced in the market in the thirty years prior to 2010. Finally, we include the natural logarithm of average R\&D investments in the years 2006-2010 as proxy of company's R\&D Investment (Ahuja, 2000; Soh, 2003, Bae and Gargiulo, 2004; Salman and Saives, 2004, Vanhaverbeke et al., 2012).

\section{Data analysis}

\subsection{Descriptive data analysis}

Table 2 illustrates the descriptive statistics and the correlation matrix between the variables of interest namely new patents, age, size, R\&D investment, product stock, collaboration experience in SCoK, centrality and structural holes.

----Please insert Table 2 about here---

From Table 2, it is clear that both the variables Centrality and Structural Holes are correlated with Coll_Exp_SCoK. The high value of correlation between these two explanatory variables supports the choice of testing the mediation effect. Because the predictor is supposed to cause the mediator variable, these variables should be highly correlated (Baron and Kenny, 1986).

\subsection{Regression analysis}

The dependent variable 'new patents developed (NPatD)' is a count variable that takes only nonnegative integer values, that is the number of biotechnological patents a company successfully developed in the years 2010-2012. A Poisson regression approach provides a natural model for such typology of data (Hausman et al., 1984). However, a Poisson regression assumes that the mean and variance of the count variable are equal. This assumption is likely to be violated since over-dispersion usually occurs in new patents count data. Over-dispersion requires the use of a negative binomial estimation (Un et al., 2010); therefore, we test our hypotheses by using a negative binomial regression. For all models we test for multi-collinearity issues using variable inflation factor (VIF) and tolerance. The problem of multi-collinearity may occur when VIF is higher than 10 (Hair et al., 2006). In data analysis, none of the regressions registers values of VIF and tolerance out of the prescribed threshold. Hence multi-collinearity is not an issue with our data.

Table 3 provides an overview of the results of the regression analysis. Model 1 is the base-line model including only the control variables. Here, all the variables are significant, with the exception of the 
control Age. We find a negative relation between Size and company's number of patents, meaning that established larger companies might have a different focus in their innovation process. The coefficient of R\&D investment is positive and significantly related to company's ability to develop new patents, meaning that the higher $R \& D$ investments turn into increasing innovative output. Finally, Product Stock also has a positive impact on company's ability to develop new patents, meaning that companies, who have matured with great number of products over time, have developed technological capabilities and R\&D know-how that positively improves their patent propensity.

Model 2 (see Table 3) introduces and tests collaboration experience in SCoK as explanatory variable. The significant and positive impact of the variable Coll_Exp_SCoK on the number of developed patents corroborates our first hypothesis (H1 - Path A).

Model 3 (see Table 3) tests the other relationship investigated in this paper, that is, structural embeddedness in SCoK and new patent development (Path B). We find that Centrality and Structural Holes have respectively a positive and negative effect on the new patent development. This result supports the hypothesis H2.a, but rejects the H2.b.

To test the mediating roles of Centrality and Structural Holes (H3.a and H3.b) on the relationship between collaboration experience and new patent development (Path $\mathrm{C}+\mathrm{B}$ ) we employ the casual step approach proposed by Baron and Kenny (1986). Accordingly, mediation involves estimating three regressions: first, we regress the mediators Centrality and Structural Holes on the predictor Coll_Exp_SCoK (Models 4 and 5); second, we regress the criterion NPaTD on the predictor Coll_Exp_SCoK (Model 2); third, we regress the criterion on both the predictor and the mediator (Model 6).

Perfect mediation holds if the predictor variable has no significant effect on the criterion when the mediator variable is controlled. If the effect of the independent variable on the dependent variable is less in the third equation than in the first, partial mediation holds. Hoyle and Robinson (2003) recommended that the reliability of mediator should be at least 0.90 . The correlation between the independent variable and each predictor turns into multi-collinearity when both the dependent variable and the mediator are included in the same model. For this reason, it is recommended to examine not only the significance of the coefficient but also their absolute size (Baron and Kenney, 1986).

Models 4 and 5 show the significant effect of the independent variable (Coll_Exp_SCoK) on both the mediators (Centrality, Structural Holes). Further, we find that Coll_Exp_SCoK has no effect when the mediators are controlled (Model 6). This result strongly supports our research hypotheses H3.a and H3.b (see Table 3). 
----Please insert Table 3 about here----

\section{Research findings and Discussion}

This study represents a step towards developing a more comprehensive understanding of innovation openness and this was motivated by important limitations of research on R\&D purchasing and selling practices and firm innovation. Current literature has indeed largely ignored the mediating effect of the firm's network positioning within the SCoK between R\&D collaboration experience and the innovation outcome. In order to fill this gap in the area of $R \& D$ collaboration, we try to conceptualize the supply chain at the R\&D level. This study brings to the attention of managers the need to consider not just the dyadic relationships with R\&D suppliers and buyers, but consider their firm's position within the whole SCoK.

Indeed, when making $R \& D$ purchasing and selling decisions, managers have to take into account precise considerations about the position of their firm within the SCoK, and meanwhile have not to neglect the effect of information volume and diversity coming from the SCoK (Burt, 1992; Koka and Prescott, 2002).

While nowadays we are assisting to the establishment of supply chains of R\&D in which companies position themselves as suppliers and buyers of $R \& D$ commodities (the paper shows empirical evidence for this) neither the literature on open innovation nor the literature on supply chain management do explicitly consider supply chain issues in open innovation processes. This study addressed this limitation by focusing on the supply chain of knowledge as opposed to the physicalgood supply chain. We found evidence, indeed, that in biotechnology industry, flows of products are often replaced by flows of patents and other R\&D commodities; consequently, the physical-goods supply chain is replaced by the SCoK. Specifically, we investigate the relationships among Collaboration Experience in SCoK, Structural Embeddedness in SCoK, and New Patent Development.

Regarding the first path (path A in figure 2), we drew on research on OI literature (Chesbrough, 2003; Laursen and Salter, 2006) to predict the influence of practices like purchasing and selling R\&D on the firm's innovation performance. Regarding the paths $\mathrm{B}$ and $\mathrm{C}+\mathrm{B}$, we built on research on social capital theory (Coleman, 1988; Burt, 1992; Adler and Kwon, 2002; Koka and Prescott, 2002; Wu, 2008; Malik, 2012) to consider how the amount of collaboration experience the firm accumulates during the years, affects its structural embeddedness within the network of knowledge (path C); and how the information volume and diversity the firms gets from its partners thanks to its position, influence its patent productivity (path B). In doing so, this study moves beyond the dual market 
structure perspective (Pisano, 1991) typically used in biotech industry research and open new scenarios for studying this market which appears to be more complex.

The key findings of this study are: (1) accumulating experience in SCoK collaborations facilitates the development of new patents; (2) the centrality of the company within the SCoK also facilitates the development of new patents; (3) conversely, bridging structural holes slows the patent development process; (4) centrality and structural holes position are two means by which the experience in SCoK collaborations is translated into new patents.

First, we found that the positive relationship that in NPD processes usually exists between collaboration experience with suppliers/customers and NPD performance, also occurs in the SCoK, where the products are mainly $R \& D$ commodities. In fact, the positive effect of collaboration practices, as well as collaborative competences, on the NPD process has been largely demonstrated in the supply chain management literature on NPD (Mishra and Shah, 2009) and has been justified in terms of the value creation and knowledge sharing arising from the relational nature of these bilateral agreements (Menguc et al., 2014). However, besides collaborating with material-flow supply chain partners, a firm increases its collaboration experience also by purchasing and/or selling R\&D services, projects, intellectual properties, and patents to/by other firms (Tsai and Wang, 2009; Chiaroni et al., 2010; Mazzola et al., 2012). Our analysis insists the result that the patent productivity of a company depends on maturity of the company experience in collaborating with SCoK partners. The reason underlying this phenomenon is that in the high-tech Industries, the objects of supply chain exchanges are often R\&D commodities; by keeping selling and purchasing these commodities the company cumulates its experience in collaborative partnerships. This, in turn, increases the company' absorptive capacity as a result of a process in which the stock of previous relationships (for example, in-licensing of patents) triggers the development of collaborative capital as a mean to orchestrate new collaborations. Also, consistent with prior works on open innovation, this finding suggests that relying on external already developed knowledge and technology enables a firm to improve its innovation performance since the firm uses suppliers' systems and mechanisms that facilitate the access to new and complex knowledge (Laursen and Salter, 2006).

Second, we found that the positive relationship that usually exists between social capital accumulation gained from being centrally positioned within the supply chain and operational performance (Autry and Griffis 2008; Villena et al. 2011, Kim 2014), also occurs in the SCoK: patent productivity of a company depends on how much the company positions itself in a central position respect to the SCoK partners. Also, in line with empirical results of other researches in the field of social capital (Ahuja, 2000; Salman and Saives, 2004; Gilsing et al. 2008; Vanhaverbeke et al. 2012) we found that being 
structural embedded in the SCoK enhances company's ability to develop new patents because the company benefits from the information volume arising from its central position (Koka and Prescott, 2002).

Third, against our expectation, we found a negative relationship between social capital accumulation gained from owning a structural holes position within the SCoK and patent performance. This result somehow reflects the debate in the social capital literature that offers different perspective on the effects of structural holes. The school of Burt (1992) argues that there exists a positive link between bridging structure holes and firm performance, mostly economic and financial performance (Zaheer and Bell, 2005, Shipilov, 2006; Shipilov and Li, 2008). Moreover, even in the area of innovation management, some studies found that a firm occupying a position that bridges network clusters is able to improve its patent propensity (e.g. Padula, 2008). Contrarily, the school of Coleman (1988) claims that structural holes positions deteriorate the innovative propensity of a firm. Indeed, having a structural holes position exposes the firm to a higher volume of diverse information (Gnyawali and Madhavan, 2001); to recognize, assimilate, transform, and exploit this information, the firm must put greater effort and resources (Cohen and Levinthal, 1990) and absorptive capacity problems become highly significant. In this direction, Ahuja (2000) empirically finds a negative influence between structural holes and patent propensity of a company. The basic conclusion that emerges from the contrasting result between Ahuja's (2000) and Padula's (2008) studies is that the effect of structural holes on patent productivity is context dependent. Ahuja (2000, pag. 451) suggests indeed that "[...] When developing a collaborative milieu and overcoming opportunisms are essential to success, closed networks are likely to be more beneficial. When speedy access to diverse information is essential, structural holes are likely to be advantageous". Our research setting surely responds to the first category: we have biotech competitors who are building collaboration experience, who are very sensitive to avoid any risk of opportunistic behaviour of the partner, and who are not very much interested in speedy access to diverse information given the very long time related to the innovation process in this industry (e.g. the time to develop a new drug is on average 12 years long, Rothaermel and Deeds 2004).

Fourth, we set out to investigate whether the experience in collaborating indirectly influence patent development, specifically through the mediation of structural embeddedness. We, indeed, expected that the structural embeddedness of the company within the SCoK can be seen as a consequence of its experience in collaborating. In turn, we demonstrated that the structural embeddedness impact company's propensity in developing patents. We found that company's positioning in SCoK, in both the dimensions of centrality and structural holes, plays a mediating role in the relationships between collaboration experience and new patent development. The collaboration experience is found to 
shapes structural embedded mechanisms, which then causes better performance. The two features of structural embeddedness fully mediate the collaboration experience-new patent development relationship, since the effect of collaboration experience on new patent development is not significant when controlling for centrality and structural holes (Model 6). This result corroborates our intuition that by maturating collaboration experience the company develops overtime an extensive network of relationships that locate the company in a specific position identified by a given level of centrality and structural holes. In turn, this position shapes a certain level of information volume and diversity that flows through the company and leads to superior performance in terms of patent productivity. This last finding contributes to the supply chain management literature, which explores the relationships between vertical and horizontal collaboration experience of the firm and its innovation performance (Ragatz et al., 2002; Petersen et al., 2005; Homburg and Stock, 2004; Koufteros et al., 2005; Humphreys et al., 2007; Song and Di Benedetto, 2011). It also contributes to the literature on open innovation, which explores the linkages between acquiring and selling R\&D and innovation outcomes (Chesbrough, 2003; West and Bogers, 2013; Sampson, 2007; Un et al., 2010). Indeed, it brings to the attention of the researchers that the actual reason behind the benefits of such a collaboration experience has to be searched in the social capital that such collaborations will create: specifically, the consequences of collaboration experience in terms of firm's innovation performance mainly depend on the position that the film will take within the SCoK due to the collaboration experience it has.

These results have interesting implications for practice. In the biotech industry, companies increasingly tend to externally purchase and sell different typologies of R\&D commodities. Due to the emergence of such $R \& D$ market, each company is asked to manage a new kind of emerging supply chain, namely the supply chain of knowledge, and to increase its ability to manage collaborations with their SCoK partners. The more such an ability increases, the more benefits arise in terms of innovation outcome, e.g. number of patent registered. On the other side, while the company increases its collaboration experience it unconsciously positions itself within the SCoK, for instance in terms of its centrality and structural holes position in the network. We found that the precise position it takes will mediate the final effect of the collaboration experience on the performance. While the level of centrality positively mediates such an effect, a structural holes position will reduce the benefit. This result strongly suggests that managers should make precise decisions about their company's positioning strategy within the SCoK. Given that such position is gained by the specific collaborations and agreements the company signs with its R\&D suppliers and buyers, the recommendation is thus to select those partners that allow the company to increase its centrality and avoid bridging structural holes in the network. 
Actually, things are more complicated than this. Indeed, the position of the company within the network besides depending on endogenous factors, such as company's decisions (e.g. the company selects its direct suppliers and buyers), also depends on exogenous factors which are not entirely under the firm's control. For example, the centrality (at least in the way we measured this value in this paper) also depends on the company indirect centrality, i.e. the centrality of its suppliers and buyers, which is not very well controllable and manageable by the company. Thus, the effectiveness of managers' decisions regarding their collaboration experience within the SCoK on the company propensity in developing new patents partially depends on exogenous factors. In conclusion, managers can make some decisions to position their company within the network, but, at some extent, undergo their network structure characteristics (e.g. the position of the partners within the network), and thus have to make their SCoK decisions also according to these.

\section{Conclusion and future work}

In this paper, we tried to identify the role of collaborations in the SCoK. We also tried to understand the link among SC collaboration specific to new patent development, social capital arising from this collaboration and new patent performance. By validating our first research hypothesis, it is clear that the higher the level of collaboration experience in SCoK, the higher the number of newly developed patents. This finding insists that experience in the SCoK collaborations is the key success factor for development of new patents. It is in line with many other findings in the area of physical supply chains (Ramanathan and Gunasekaran, 2014).

While centrality within the SCoK supports the new patent development of the companies (H2asupported), by bridging structural holes the companies slow down the patent development process (H2b-not supported). This result indicates the importance of companies' positioning in the SCoK. Some ways of being structurally embedded in the SCoK (e.g. being central) is good, other ways (e.g. bringing holes) is not.

Our data analysis validated two other research hypotheses H3a and H3b. It indicates that, at least in the biotech industry, the positive link between collaboration experience and the number of newly developed patents is indirect. The collaboration experience shapes structural embedded mechanisms, which then causes better performance.

This research presents a number of limitations that also ask for further research to be done. Among them, it has to be said that our results are based on secondary data from BioWorld, a biotechnology industry database containing information about biotech companies' agreements; data from USPTO, a US database containing information on firm's patents; and data from firm's annual reports. The secondary source data analysis proposed in this paper, lacks of a confirmatory empirical analysis that 
can effectively demonstrate that our assumptions about the interpretation of data are appropriate. For example we should investigate whether by keeping signing $R \& D$ purchasing and selling agreements with R\&D suppliers and buyers will actually increase the firm's experience in collaboration. Indeed the secondary-data analysis approach did not allow us investigate these issues any deeper. For this reason, further empirical research based on company case studies and based on primary and real-time data would help to generalize the results in a more concrete way.

Secondly, because the intention is to analyse the supply chain of knowledge, this study focuses on the biopharmaceutical industry (traditionally involved in innovation processes) and excludes other types of industries. Although this approach is appropriate, it would be unwise to generalise the findings too broadly to other industries and cultural contexts. Further research should investigate our conceptual model in other industries.

Thirdly, our research is built on social capital theory to consider how the position of the firm within the SCoK may affect structural embeddedness, and how its levels of centrality and structural holes mediate the linkage between collaboration experience and patent productivity. However, social capital is a multidimensional construct that yields different dimensions, not only in the form of structural embeddedness but also of relational and cognitive embeddedness (Koka and Prescott, 2002; Villena et al. 2011). A complete comprehension of the mediating role of social capital would have required taking into account a number of network characteristics other than centrality and structure holes, such as cliques, repeated ties, shared values, and so on. 


\section{References}

Acquaah, M. (2007), "Managerial social capital, strategic orientation, and organizational performance in an emerging economy", Strategic Management Journal, Vol. 28 pp.12, No. 12351255.

Adler, P.S., Kwon, S.W., 2002. Social capital: prospects for a new concept. Academy of Management Review, 27:1, 17-40.

Ahuja, G. (2000), "Collaboration networks, structural holes, and innovation: A longitudinal study", Administrative Science Quarterly, Vol. 45 No. 3, pp. 425-455.

Al-Laham, Andreas, Terry L. Amburgey, and Kimberly Bates. "The dynamics of research alliances: Examining the effect of alliance experience and partner characteristics on the speed of alliance entry in the biotech industry." British Journal of Management 19.4 (2008): 343-364.

Arundel, A., Kabla, I., 1998. What percentage of innovations are patented? Empirical estimates for European firms. Research Policy 27 (2), 127-141.

Autry, Ch.W., Griffis, S., 2008. Supply chain capital: the impact of structural and rela- tional linkages on firm execution and innovation. Journal of Business Logistics 29 (1), 157-173.

Bae, J. and Gargiulo, M. (2004), "Partner substitutability, alliance network structure, and firm profitability in the telecommunications industry", Academy of Management Journal, Vol. 47, pp. 843-59.

Baron, R. M., \& Kenny, D. A. (1986), "The moderator-mediator variable distinction in social psychological research: Conceptual, strategic, and statistical considerations", Journal of personality and social psychology, Vol. 51 No. 6, pp. 1173.

Barratt, M. (2004), "Understanding the meaning of collaboration in the supply chain", Supply Chain Management: An International Journal, Vol. 9 No. 1, pp. 30-42.

Battistella, C., and Nonino, F. (2013), "Exploring the impact of motivations on the attraction of innovation roles in open innovation web-based platforms", Production Planning \& Control, Vol. 24, No. 2-3, pp. 226-245.

Benassi, M., Di Minin, A. (2009). "Playing in between: patent brokers in markets for technology", $R \& d$ Management, Vol. 39 No. 1, pp. 68-86.

Bendoly, E., Rosenzweig, E. D., \& Stratman, J. K. (2009). The efficient use of enterprise information for strategic advantage: A data envelopment analysis. Journal of Operations Management, 27(4), 310-323.

Billitteri, C., Lo Nigro, G. and Perrone, G. (2013). „Drivers influencing the governance of inter-firm relationships in the biopharmaceutical industry: an empirical survey in the Italian contextee. Technology Analysis and Strategic Management, 25, 107-26.

Birch, K. (2008). 'Alliance-driven governance: Applying a global commodity chains approach to the U.K. biotechnology industry’. Economic Geography, 84, 83-103.

Bonacich, P. (1987), "Power and centrality: a family of measures", American Journal of Sociology, Vol. 92, pp. 1170-82.

Borgatti, S.P., Everett, M.G. and Freeman, L.C. (2002), Ucinet 6 for Windows. Harvard, MA: Analytic Technologies.

Bourdieu, P., and Wacquant, L. (1992). An invitation to reflexive sociology. Chicago, IL: University of Chicago. 
Bunduchi, R. (2013). Trust, partner selection and innovation outcome in collaborative new product development. Production Planning \& Control, 24(2-3), 145-157.

Burt, R. S. (1992), "The social structure of competition", Networks and organizations: Structure, form, and action, Vol. 57, pp. 91.

Burt, R. S. (2000), "The network structure of social capital", Research in organizational behavior, Vol. 22, pp. 345-423.

Büyüközkan, G and Arsenyan, J. (2012) Collaborative product development: a literature overview, Production Planning \& Control, 23:1, 47-66

Caniato, F., and Größler, A. (2015). The moderating effect of product complexity on new product development and supply chain management integration. Production Planning \& Control, (aheadof-print), 1-12.

Chesbrough, H. (2003), Open Innovation. Cambridge, MA: Harvard University Press.

Chiang, Y. H., Hung, K. P. (2010), "Exploring open search strategies and perceived innovation performance from the perspective of inter-organizational knowledge flows", $R \& d$ Management, Vol. 40, pp. 3, 292-299.

Chiaroni, D., Chiesa, V., Frattini, F., 2010. Unraveling the process from closed to open innovation: evidence from mature, asset-intensive industries. R\&D Manage. 40 (3), 222-245.

Cohen, W.M. and Levinthal, D. (1990), "Absorptive capacity: a new perspective on learning and innovation", Administrative Science Quarterly, Vol. 35 Vol. 1, pp. 128-152.

Coleman, J.S. (1988) Social capital in the creation of human capital. American Journal of Sociology, 94, 95-120.

Cousins, P.D., Handfield, R.B., Lawson, B., Petersen, K.J., 2006. Creating supply chain relational capital: the impact of formal and informal socialization processes. J. Oper. Manage. 24 (6), 851863.

Cyert, R. M., March, J. G. (1963), “A behavioral theory of the firm”, Englewood Cliffs, NJ, 2.

Dahlander, L., Gann, D. M. (2010), “How open is innovation?”, Research policy, Vol. 39 No. 6, pp. 699-709.

Deeds, D.L., Decarolis, D.M. (1999) “The impact of stocks and flows of organizational knowledge on firm performance: an empirical investigation of the biotechnology industry". Strategic Management Journal, Vol 20 No 10, pp 953-968.

Ettlie, J.E. and Pavlou, P.A. (2006), “Technology-based new product development partnerships”, Decision Sciences, Vol. 37 No. 2, pp. 117-147.

Frankfort-Nachmias, C. and D. Nachmias (1992) Research Methods in the Social Sciences. Edward Arnold, London (Fourth Edition).

Garengo, P., and Panizzolo, R. (2013). Supplier involvement in integrated product development: evidence from a group of Italian SMEs. Production Planning \& Control, 24(2-3), 158-171.

Gassmann, O., Enkel, E. (2004), "Towards a theory of open innovation: three core process archetypes". R\&D management conference, pp. 1-18.

Gassmann, O., Enkel, E. and Chesbrough, H. (2010), "The future of open innovation", $R \& D$ Management, Vol. 40 No. 3, pp. 213-221.

Gilsing, V., Nooteboom, B., Vanhaverbeke, W., Duysters, G., van den Oord, A. (2008), "Network embeddedness and the exploration of novel technologies: Technological distance, betweenness centrality and density", Research Policy, Vol. 37, No.10, pp. 1717-1731. 
Gnyawali, D. R. and Madhavan, R. (2001) "Cooperative networks and competitive dynamics: a structural embeddedness perspective”. Academy of Management Review, 26, 431-45.

Granovetter, M. (1985), "Economic action and social structure: the problem of embeddedness", Am. J. Sociol. 91 (3), 481-510.

Granovetter, M. (2005), “The impact of social structure on economic outcomes”. J. Econ. Perspect. 19 (1), 33-50.

Granovetter, M.S. (1973) The strength of weak ties. American Journal of Sociology, 78, 1360-1380.

Granovetter, M.S. (1992), "Problems of explanation in economic sociology". In: Nohria, N., Eccles, R. (Eds.), Networks and Organizations: Structure, Form and Action. Harvard Business School Press, Boston, MA, pp. 25-56.

Gulati, R. (1995), "Does familiarity breed trust? The implications of repeated ties for contractual choice in alliances", Academy of Management Journal, Vol. 38 No.1 , pp. 85-112.

Hair Jr., J.F., Black, W.C., Babin, B.J., Anderson, R.E., Tatham, R.L. (2006), “Multivariate Data Analysis", Pearson-Prentice Hall, New Jersey.

Hamel, G., Doz, Y., \& Prahalad, C. (1989), “Collaborate with your competitors”, Harvard business review, Vol. 67 No.1, pp. 133-139.

Hausman, J., Hall, B. and Griliches, Z. (1984), "Econometric models for count data with an application to the patents-R\&D relationship", Econometrica, Vol. 52, pp. 909-38.

He, Y., Keung Lai, K., Sun, H., \& Chen, Y. (2014). The impact of supplier integration on customer integration and new product performance: The mediating role of manufacturing flexibility under trust theory. International Journal of Production Economics, 147, 260-270.

Homburg, C., Stock, R.M., 2004. The link between sales people's job satisfaction and customer satisfaction in a business-to-business context: a dyadic analysis. J. Acad. Market. Sci. 32 (2), 144158.

Hoyle, R. H., \& Robinson, J. C. (2004), "Mediated and moderated effects in social psychological research", Handbook of methods in social psychology, pp. 213-233.

Hsuan, J., and Mahnke, V. (2011), “Outsourcing R\&D: a review, model, and research agenda”, $R \& D$ Management, Vol. 41 No. 1, pp. 1-7.

Huang, J. Y., Chou, T. C., Lee, G. G. (2010), “Imitative innovation strategies: understanding resource management of competent followers", Management Decision, Vol. 48 No. 6, pp. 952-975.

Humphreys, P., Huang, G., Cadden, T., McIvor, R., 2007. Integrating design metrics within the early supplier selection process. J. Purch. Supply Manag. 13 (1), 42-52.

Jean, R.J., Kim, D. and Sinkovics, R.R. (2012), "Drivers and performance outcomes of supplier innovation generation in customer-supplier relationships: the role of power-dependence", Decision Sciences, Vol. 43 No. 6, pp. 1003-1038.

Johnsen, T.E. (2011), "Supply network delegation and intervention strategies during supplier involvement in new product development", International Journal of Operations \& Production Management, Vol. 31 No. 6, pp. 686-708.

Khoja, F., Adams, J., Kauffman, R., 2010. A temporal model of vertical relationships. J. Bus. Bus. Market. 17 (3), 279-307.

Kim, D. Y. (2014). Understanding supplier structural embeddedness: A social network perspective. Journal of Operations Management, 32(5), 219-231. 
Kline, S. J., \& Rosenberg, N. (1986),"An overview of innovation", The positive sum strategy: Harnessing technology for economic growth, 275, 305.

Kogut, B. (1988), "Joint ventures: Theoretical and empirical perspectives", Strategic management journal, Vol. 9 No.4, pp. 319-332.

Koka, B. and Prescott, J.E. (2002), "Strategic alliances as social capital: A multidimensional view", Strategic Management Journal, Vol. 23 No. 9, pp. 795-816.

Koufteros, X., Vonderembse, M. and Jayaram, J. (2005), "Internal and external integration for product development: the contingency effects of uncertainty, equivocality, and platform strategy", Decision Sciences, Vol. 36 No. 1, pp. 97-133.

Krause, D.R., Handfield, R.B. and Tyler, B.B. (2007), "The relationships between supplier development, commitment, social capital accumulation and performance improvement", Journal of Operations Management, Vol. 25 No. 2, pp. 528-545.

Laosirihongthong, T., Prajogo, D. I., and Adebanjo, D. (2014). The relationships between firm's strategy, resources and innovation performance: resources-based view perspective. Production Planning \& Control, 25(15), 1231-1246.

Laursen, K. and Salter, A. (2006), "Open for innovation: the role of openness in explaining innovation performance among U.K. manufacturing firms”, Strategic Management Journal, Vol. 27 No. 2, pp. 131-150.

Lawson, B., Tyler, B.B., Cousins, P.D., 2008. Antecedents and consequences of social capital on buyer performance improvement. J. Oper. Manage. 26 (3), 446-460.

Li, W., Veliyath, R., \& Tan, J. (2013). Network characteristics and firm performance: an examination of the relationships in the context of a cluster. Journal of Small Business Management, 51(1), 122.

Lichtenthaler, U. (2009) "Outbound open innovation and its effect on firm performance: examining environmental influences", $R \& D$ Management, Vol. 39, No. 4, pp.317-330.

Malik, T. (2012). Disparate association between alliance social capital and the global pharmaceutical firm's performance. International Business Review, 21(6), 1017-1028.

Mazzola, E., Bruccoleri, M., Perrone, G., 2012. The effect of inbound, outbound and coupled innovation on performance. Int. J. Innov. Manage. 16 (6), 1240008.

Mazzola, E., Perrone, G., \& Kamuriwo, D. S. (2014). Network embeddedness and new product development in the biopharmaceutical industry: The moderating role of open innovation flow. International Journal of Production Economics.

Menguc, B., Auh, S., \& Yannopoulos, P., 2014. Customer and supplier involvement in design: The moderating role of incremental and radical innovation capability. Journal of Product Innovation Management, 31:2, 313-328.

Min, S., Kim, S. K., \& Chen, H. (2008). Developing social identity and social capital for supply chain management. Journal of business logistics, 29(1), 283-304.

Mishra, A. A., and R. Shah. 2009. In union lies strength: Collaborative competence in new product development and its performance effects. Journal of Operations Management 27: 324-38.

Mody, A. (1990). Institutions and dynamic comparative advantage: the electronics industry in South Korea and Taiwan. Cambridge Journal of Economics, 291-314.

Msanjila, S. S., and Afsarmanesh, H. (2011). On modelling evolution of trust in organisations towards mediating collaboration. Production Planning \& Control, 22(5-6), 518-537. 
Nelson, R., Winter, S., 1982. An Evolutionary Theory of Economic Change. Harvard University Press, Cambridge, MA.

Orsenigo, L. (1989) "The Emergence of Biotechnology: Institutions and Markets in Industrial Innovation". St. Martin's Press, New York.

Padula, G. (2008), "Enhancing the innovation performance of firms by balancing cohesiveness and bridging ties", Long Range Planning, Vol. 41 No. 4, pp. 395-419.

Pérez-Luño, A., Cabello Medina, C., Carmona Lavado, A., Cuevas Rodríguez, G. (2011), "How social capital and knowledge affect innovation", Journal of Business Research, Vol. 64 No. 12, pp. 1369-1376.

Petersen, K.J., Handfield, R.B., Ragatz, G.L., 2005. Supplier integration into new product development: coordinating product, process and supply chain design. Journal of Operations Management 23 (3/4), 371-388.

Pisano, G. P. (1991). The governance of innovation: vertical integration and collaborative arrangements in the biotechnology industry. Research Policy, 20(3), 237-249.

Powell, W. W., Koput, K. W., Smith-Doerr, L., \& Owen-Smith, J. (1999), "Network position and firm performance: Organizational returns to collaboration in the biotechnology industry", Research in the Sociology of Organizations, Vol. 16 No. 1, 129-159.

Ragatz, G.L., et al., 2002. Benefits associated with supplier integra- tion into new product development under conditions of technology uncertainty. Journal of Business Research 55, 389400.

Ramanathan, U., and Gunasekaran, A. (2014). Supply chain collaboration: Impact of success in longterm partnerships. International Journal of Production Economics, 147, 252-259.

Ritter, T., Wilkinson, I. F., \& Johnston, W. J. (2004). Managing in complex business networks. Industrial Marketing Management, 33, 175-183.

Riccobono, F., Bruccoleri, M., Harrigan, K.R., Perrone, G. (2014). Do horizontal relationships matter to production and operations managers?. International Journal of Production Research, 52 (16), 4731-4746.

Romero, D., and Molina, A. (2011). Collaborative networked organizations and customer communities: value co-creation and co-innovation in the networking era. Production Planning \& Control, 22(5-6), 447-472.

Rothaermel, F.T. (2001), “Complementary assets, strategic alliances, and the incumbent's advantage: an empirical study of industry and firm effects in the biopharmaceutical industry", Research Policy, Vol. 30, pp. 1235-1251.

Rothaermel, F.T. and Deeds, D.L. (2004), "Exploration and exploitation alliances in biotechnology: a system of new product development", Strategic Management Journal, Vol. 25 No. 3, pp. 201221.

Rowley, T., Behrens, D., \& Krackhardt, D. (2000). Redundant governance structures: An analysis of structural and relational embeddedness in the steel and semiconductor industries. Strategic Management Journal, 21(3), 369-386.

Sabatier, V., Mangematin, V. and Rousselle, T. (2010), "Orchestrating networks in the biopharmaceutical industry: small hub firms can do it", Production Planning and Control, Vol. 21 No. 2, pp. 218-28.

Salman, N. and Saives, A.L. (2005), "Indirect networks: An intangible resource for biotechnology innovation”, $R \& D$ Management, Vol. 35 No. 2, pp. 203- 15. 
Sammarra, A., Biggiero, L. (2008), "Heterogeneity and specificity of Inter-Firm knowledge flows in innovation networks", Journal of Management Studies, Vol. 45 No. 4, pp. 800-829.

Schilling, M. and Phelps, C. (2007), "Interfirm collaboration networks and knowledge creation: the impact of large scale network structure on firm innovation", Management Science, Vol. 53 No. 7 , pp. 1113-1126.

Shan, W., Walker, G., Kogut, B. (1994) "Interfirm cooperation and startup innovation in the biotechnology industry”, Strategic Management Journal, Vol. 15, No. 5, pp. 387-394.

Shipilov, A. V. (2006). Network strategies and performance of Canadian investment banks. Academy of Management Journal, 49(3), 590-604.

Shipilov, A. V., and S. Li. 2008. Can you have your cake and eat it too? Structural holes' influence on status accumulation and market performance in collaborative networks. Administrative Science Quarterly 58 (1): 73-108.

Soh, P. H. (2003), "The role of networking alliances in information acquisition and its implications for new product performance", Journal of Business Venturing, Vol. 18 No. 6, pp. 727-744.

Song, L.Z., Song, M. and Di Benedetto, C.A. (2011), "Resources, supplier investment, product launch advantages, and first product performance", Journal of Operations Management, Vol. 29 No. 1/2, pp. 86-104.

Song, M., Droge, C., Hanvanich, S., \& Calantone, R. (2005), "Marketing and technology resource complementarity: an analysis of their interaction effect in two environmental contexts", Strategic Management Journal, Vol. 26 No.3, pp. 259-276.

Stewart, D. W. (1984). Secondary Research: Information Sources and Methods. Sage, Beverly Hills.

Swink, M., Narasimhan, R. and Wang, C. (2007), "Managing beyond the factory walls: Effects of four types of strategic integration on manufacturing plant performance", Journal of Operations Management, Vol. 25 No.1, pp. 148-164.

Teece, D. J., Pisano, G. (1994), “The dynamic capabilities of firms: an introduction”, Industrial and corporate change, Vol. 3 No. 3, pp. 537-556.

Tiwana, A., 2008. Do bridging ties complement strong ties? An empirical examina- tion of alliance ambidexterity. Strat. Manage. J. 29 (3), 251-272.

Tsai, K.H. and Wang, J.C. (2009), "External technology sourcing and innovation performance in LMT sectors: an analysis based on the Taiwanese technological innovation survey", Research Policy, Vol. 38 No. 3, pp. 518-526.

Un, C. A., Cuervo-Cazurra, A., \& Asakawa, K. (2010), "R\&D collaborations and product innovation", Journal of Product Innovation Management, Vol. 27 No. 5, pp. 673-689.

Vanhaverbeke, W., Gilsing, V., Beerkens. B. and Duysters, G. (2009), "The role of alliance network redundancy in the creation of core and non-core technologies: a local action approach", Journal of Management Studies, Vol. 46 No. 2, pp. 215-244.

Vanhaverbeke, W., Roijakkers, N., Wang, Y. (2012), “Exploring the impact of open innovation on national systems of innovation-A theoretical analysis", Technological Forecasting and Social Change, Vol. 79 No. 3, pp. 419-428.

Villena, V. H., Revilla, E., \& Choi, T. Y. (2011). The dark side of buyer-supplier relationships: A social capital perspective. Journal of Operations Management, 29(6), 561-576.

West, J., Bogers, M., 2013. Leveraging external sources of innovation: a review of research on open innovation. J. Product Innov. Manag. 〈http://dx.doi.org/10. 1111/jpim.12125. 
Wu, W.-P. (2008), "Dimensions of social capital and firm competitiveness improvement: the mediating role of information sharing", Journal of Management Studies, Vol. 45 No. 1, pp. 122146.

Zaheer, A., and Bell, G. G. (2005), "Benefiting from network position: firm capabilities, structural holes, and performance", Strategic management journal, Vol. 26 No. 9, pp. 809-82.

Zaheer, A., and Venkatraman, N. (1995). Relational governance as an interorganizationl strategy: An empirical test of the role of trust in economic exchange. Strategic Management Journal, 16(5), 373.

Zahra, Shaker A., and Gerard George. "Absorptive capacity: A review, reconceptualization, and extension." Academy of management review 27.2 (2002): 185-203. 